\title{
A Roadmap for Establishing Trust Management Strategy in E-Commerce Services Using Quality Based Assessment
}

\author{
Rath Jairak, Prasong Praneetpolgrang, Nivet Chirawichitchai \\ School of Information Technology, Sripatum University, Bangkok 10900, Thailand \\ rathjairak@gmail.com, prasong.pr@spu.ac.th, nivet.ch@spu.ac.th
}

\begin{abstract}
Trust has been reported as a key role in ebusiness, especially for a monetary based system like ecommerce. Therefore, many previous studies have been conducted to investigate the antecedents and consequences of consumer trust. But there has been little work done on establishing sensible solutions for leveraging consumer trust. Furthermore, previous studies in managerial trust have not demonstrated trust management that can illustrate a method to link their solutions with the consumers' point of view. In this paper, we therefore propose a practical roadmap for establishing trust management strategy that is consistent with consumer perceptions. Within this roadmap, firstly, a component extraction is performed on survey data in order to identify the quality criteria that actually impact buying decision process. Based on these criteria, the sensible factors for establishing trust and satisfaction are discovered from the regression analysis. Then, the prediction equations for trust and satisfaction are generated. After that the results of prediction equations are applied with a fuzzy linguistic approach in order to convert these results in linguistic terms. Finally, trust management strategy is established. By using our proposed method, website managers can identify which are the quality criteria that are consistent with their customer perceptions and they can use these criteria as a basis for improving trust and satisfaction in their websites.
\end{abstract}

Index Terms-Trust management, Trust management strategy, E-Commerce, Quality criteria, Consumer trust, Fuzzy linguistic approach.

\section{INTRODUCTION}

Trust plays a key role in electronic business (ebusiness), especially in a monetary based system like electronic commerce (e-commerce) [1]. Generally, trust is a dynamic relationship between a trustor and trustee that depends on experience, time, and context [2]. Lacking of trust in trustees is an important barrier to obstruct trustors to exchange their assets [3].

On the internet, problems related fraud, spyware, and other vulnerabilities make buyers (trustors) feel worried about exchanging their personal information and money online $[1,3,4]$. To avoid these uncertainties, some buyers are more inclined to buy from traditional stores [2].
Moreover, lack of touch and feel in online shopping can also make buyers feel more risk when interacting with online vendors (trustees) [5]. In order to reduce the possibility of interaction with ineligible vendors, online buyers need to rely on their experience and other evidence to determine which vendors/websites can be trusted $[2,5,6]$. The dynamic of trust in e-commerce is caused by a change in perceptions between inexperienced and experienced buyers $[7,8]$. Buyers who do not have much experience can evaluate a target website through second-hand knowledge and their partial experience. No prior experience with the vendors can lead buyers to hesitate to transfer their personal information and money online [7]. On the other hand, experienced buyers perceive the website as more trustworthy, more useful, and easier to use $[7,8]$.

According to the previous research in e-commerce, reputation, familiarity, information quality, security, privacy, ease of use, and usefulness are often found as the factors affecting trust for inexperienced buyers, while the provision of better support for service quality and system quality are the two most important factors that affect trust for experienced buyers. Therefore, online vendors should start their initial relationship with inexperienced buyers by providing high quality content and workable internal operation, and then decide to maintain the website for experienced buyers by providing acceptable service delivery, adequate security mechanisms, sufficient privacy protection, effective usability, and online shopping incentives [7,8,9,10,11,12,13,14,15,16,17]. In addition, online vendors should not just be concerned about the functional attributes but also about hedonic attributes (e.g., appealing layout, enjoyable and exciting activities) that have the ability to delight and satisfy customers [18].

Following the major findings discussed above, we can indicate that many previous studies in e-commerce have been conducted to investigate the antecedents and consequences of consumer trust, there has been little work done on establishing sensible concepts for leveraging consumer trust [13]. Therefore, in this paper, we develop a roadmap for establishing trust management strategy in e-commerce context that has often been found as an under-trusting context.

The rest of this article is organized as follows: Section II presents the concept of trust in e-business; quality 
criteria and the method for generating prediction equations from these criteria are introduced in section III and section IV, respectively; section V demonstrates how to illustrate the results of quality assessment in a fuzzy form; consequently, the strategic outcomes can be described in section VI; section VII summarizes the practical roadmap for establishing trust management strategy; and finally, section VIII offers the conclusions of this research.

\section{CONCEPT OF TRUST IN E-BUSINESS}

In general, research studies on technological trust identify trust within the narrow terms related to privacy, security, public key infrastructure, and other technical aspects [14]. The technical aspects of trust are basically measured through security concepts. Meanwhile, in ebusiness, trust does not occur in a vacuum. It is a concept that transfers from interpersonal belief and experience [19]. Therefore, trust in e-business, especially in consumer-driven e-commerce (such as B2C and C2C), is considered as socially-oriented trust rather than securityoriented trust [4].

Table 1. Factors Affecting Initial Trust for Inexperienced Buyers

\begin{tabular}{|c|c|}
\hline Factors & Important findings in recent research \\
\hline $\begin{array}{c}\text { Information } \\
\text { quality }\end{array}$ & $\begin{array}{l}\text { Information available on a website should be } \\
\text { accurate, current, relevant, useful, and easy to } \\
\text { understand }[7,13,14] \text {. Information quality shows a } \\
\text { major impact on initial trust [7]. }\end{array}$ \\
\hline $\begin{array}{l}\text { Security } \\
\text { and } \\
\text { privacy }\end{array}$ & $\begin{array}{l}\text { Protection of personal information and security in an } \\
\text { electronic payment system are the major concerns } \\
\text { among potential customers }[13,21,23] \text {. }\end{array}$ \\
\hline $\begin{array}{l}\text { Ease of use } \\
\text { system }\end{array}$ & $\begin{array}{l}\text { Good navigation and an easy-to-use system can } \\
\text { create initial trust }[8,23,24] \text {. }\end{array}$ \\
\hline $\begin{array}{l}\text { Usefulness } \\
\text { system }\end{array}$ & $\begin{array}{l}\text { A useful system and effective search function can } \\
\text { increase initial trust }[8,23,24] \text {. }\end{array}$ \\
\hline $\begin{array}{l}\text { Website } \\
\text { reputation }\end{array}$ & $\begin{array}{l}\text { Reputation represents social image on a website. } \\
\text { A good reputation is a valuable asset and requires } \\
\text { a long term relationship to establish }[8,10,21,23] \text {. }\end{array}$ \\
\hline Familiarity & $\begin{array}{l}\text { Familiarity is an experience based perception to } \\
\text { reduce misunderstanding about a system and service } \\
\text { operations [8]. The more familiarity, the more trust } \\
\text { customers will have on a website. }\end{array}$ \\
\hline $\begin{array}{c}\text { Trust } \\
\text { propensity }\end{array}$ & $\begin{array}{l}\text { Trust propensity is a personal experience which } \\
\text { people show faith or belief in humanity. Trust } \\
\text { propensity is very important in the phase of initial } \\
\text { trust }[8,23] \text {. }\end{array}$ \\
\hline
\end{tabular}

In order to be able to manage trust effectively, it is crucial to understand the factors influencing trust for ebusiness in each specific context [19]. In e-commerce context, trust remains challenging for researchers because of the complexity in its environment. Based on consumer perspective, not only technical criteria but also cultural, psychological, and social factors that should be taken into account to evaluate trust [4]. In previous studies, trust shows potential for increasing satisfaction and intention to purchase for the first time $[10,12,15,17]$. In the long run, trust also shows a significant direct effect on customer loyalty and indirect effect through customer satisfaction $[15,20]$.

Based on McKnight et al. [21], trust in e-commerce can be separated into two stages: 1) trust in an exploratory stage or initial trust for inexperienced buyers and 2) trust in a commitment stage or ongoing trust for experienced buyers [22].

According to the important findings described in Table 1 , we have found that the factors associated with the development of initial trust can be classified into three distinctive groups as follows: 1) personal traits, 2) social image, and 3) website quality [7,8,21,23]. Personal traits are the factors that reflect personal belief and individual experience. Social image refers to the social agreements about the website. However, it is complicated to manage both personal traits and social image in practice. These two factors are beyond the scope of website operation, and it also takes a long time to establish a good image from public society. For this reason, online vendors should develop and maintain consistency for all quality aspects in their internal process. With this sincere expression, shoppers will perceive the website as the best destination for delivering high quality products and services. Eventually, the shoppers will show their trust and not hesitate to come back.

Table 2. Factors Affecting Trust and Satisfaction in Experienced Buyers

\begin{tabular}{|c|l|}
\hline Factors & \multicolumn{1}{|c|}{ Important findings in recent research } \\
\hline $\begin{array}{c}\text { Information } \\
\text { quality }\end{array}$ & $\begin{array}{l}\text { Information quality shows a weaker effect on } \\
\text { trust for experienced buyers than inexperienced } \\
\text { ones [7]. }\end{array}$ \\
\hline $\begin{array}{c}\text { Security and } \\
\text { privacy }\end{array}$ & $\begin{array}{l}\text { Privacy protection has a higher effect on } \\
\text { ongoing trust than security protection [14]. }\end{array}$ \\
\hline $\begin{array}{c}\text { Fulfillment and } \\
\text { responsiveness }\end{array}$ & $\begin{array}{l}\text { Fulfillment and responsiveness are the most } \\
\text { important factors that affect ongoing trust [10]. }\end{array}$ \\
\hline $\begin{array}{c}\text { Assurance } \\
\text { processes }\end{array}$ & $\begin{array}{l}\text { Assurance mechanisms, such as guarantee and } \\
\text { regulation, have a positive effect on ongoing } \\
\text { trust [24]. }\end{array}$ \\
\hline $\begin{array}{c}\text { Hedonic } \\
\text { attributes }\end{array}$ & $\begin{array}{l}\text { Fun and exciting activities can provide more } \\
\text { satisfaction for experienced buyers [11]. }\end{array}$ \\
\hline $\begin{array}{c}\text { Incentive } \\
\text { offers }\end{array}$ & $\begin{array}{l}\text { Exclusive offers from a website can increase } \\
\text { perceived value and enjoyment for experienced } \\
\text { buyers [18]. }\end{array}$ \\
\hline $\begin{array}{c}\text { Reputation } \\
\text { and trust } \\
\text { propensity }\end{array}$ & $\begin{array}{l}\text { In most cases, reputation and trust propensity } \\
\text { show a weaker effect on trust for experienced } \\
\text { buyers than inexperienced ones [7,8,14,23]. }\end{array}$ \\
\hline
\end{tabular}

Experienced buyers become more familiar with the online shopping process. They have more trust in the website operation, and expect to get more appreciated services $[7,8,24]$. The possibility of repurchase from these customers will depend not only on their positive 
experience with the previous purchase, but also on perceived benefits in the next purchase [18]. Over the long run, online vendors should be concerned with the quality attributes that can cultivate trust and increase customer satisfaction. The factors that affect both trust and satisfaction for experienced buyers are summarized in Table 2.

\section{ESTABLISHING TRUST AND SATISFACTION FROM QUALITY CRITERIA}

With the insight knowledge obtained from the literature, as presented in the previous section, we can identify the factors that affect trust and satisfaction in both initial and long term relationships. Based on these factors, we can extract the quality criteria that can be used as an important tool to assess trust and satisfaction in our approach.

ISO 8402 defines quality as: "The totality of features and characteristics of a product or service that bears on its ability to satisfy stated or implied needs". This definition indicates that proper quality criteria should provide the capability to leverage user satisfaction (or buyer satisfaction in e-commerce). Although trust has not been specified in ISO 8402 standard, trust remains the essential ingredient for interaction in the e-commerce system, as noted in the previous section. Moreover, some researchers also argued that trust and quality are inter dependent terms [25].

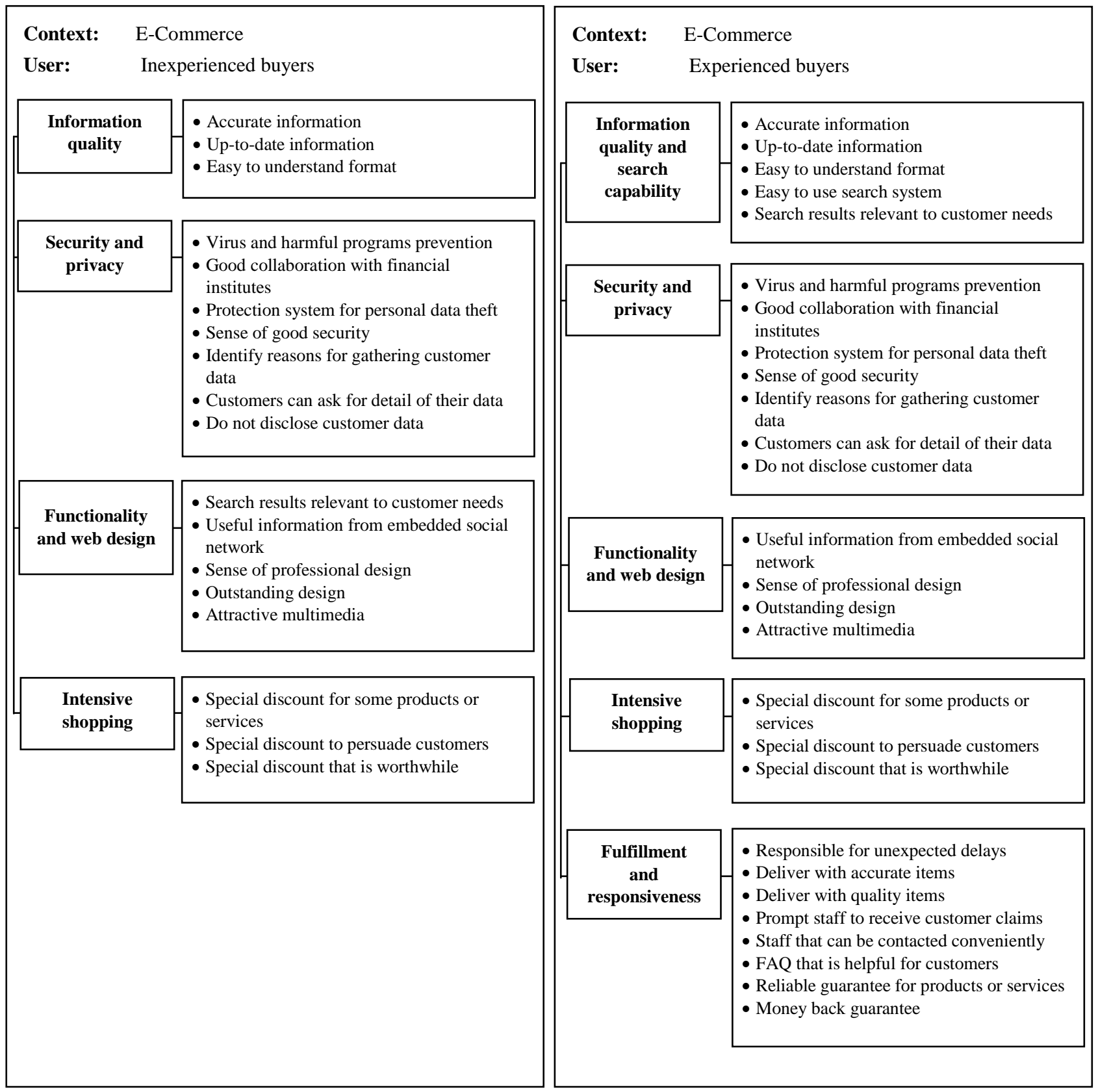

Fig 1. Quality criteria for inexperienced and experienced buyers. 
Therefore, quality criteria that can be used in practice to stimulate for both trust and satisfaction are the key components for driving e-commerce business. For this study, we define quality as the attributes or features that a website administrator should perform to leverage customer trust and satisfaction.

In order to establish quality criteria that support the above definition, we designed an instrument by using the literature provided in the previous section. The items in our instrument were updated after a pretest with 10 graduate students in information technology and 98 participations who were familiar with online shopping.

As of January 2013, the final version of the instrument was distributed to a convenience sample of 500 participants (300 undergraduate students and 200 employees) in Thailand. The participants were asked to identify a familiar website and evaluated its service quality. After inappropriate responses were suppressed, a total of 427 usable responses (represent 85.4\%) were included in the validation and reliability testing.

In the validation process, we performed a principal component analysis (PCA) with VARIMAX rotation. Components with eigen values greater than 1.0 and factor loadings exceeding the cut-off point of 0.5 were considered. Reliability of the instrument was measured by cronbach's alpha.

In order to avoid misinterpretation from incomplete shopping experience, fulfillment and responsiveness that are unfamiliar post-purchase criteria for inexperienced buyers were omitted from factor analysis. As a result, four principal components were extracted in the case of inexperienced group. The remaining items can be described as follows: 1) three items for information quality, 2) seven items for security and privacy, 3) five items for functionality and web design, and 4) three items for intensive shopping. Under the reliability testing, all components earned cronbach's alpha above 0.7. It presents an adequate level of reliability.

In terms of component extraction for experienced group, five components were extracted. Component 1 is related to information quality and search capability, component 2 related to security and privacy, component 3 to functionality and web design, component 4 to intensive shopping, and component 5 to fulfillment and responsiveness. All components earned cronbach's alpha above 0.8 . This indicates that internal consistency should be obtained.

In addition, we found some different perceptions between inexperienced and experienced buyers. Some items in functionality combined with information quality for experienced group, which caused "information quality and search capability" to be identified as the new component. As a result, the items related to "functionality and web design" remained for inexperienced buyers rather than experienced ones.

According to the extraction results from PCA, we can access the quality criteria that are consistent with customer perceptions, as illustrated in Fig. 1. Therefore, the results of website assessment from these criteria can be used to improve the features that actually impact buying decision process.

Table 3. Results of Regression Analysis on Factors Affecting Trust and Satisfaction in Inexperienced Buyers $(n=179)$

\begin{tabular}{|c|c|c|c|c|c|c|}
\hline \multirow{2}{*}{ Independent Variables } & \multicolumn{3}{|c|}{ Initial Trust } & \multicolumn{3}{|c|}{ Satisfaction } \\
\hline & $\beta$ (Beta) & T-value & Sig. level & $\beta$ (Beta) & T-value & Sig. level \\
\hline Information quality & 0.121 & 1.720 & 0.087 & $0.179 *$ & 2.517 & 0.013 \\
\hline Security and privacy & $0.154^{*}$ & 1.994 & 0.048 & $0.202 *$ & 2.585 & 0.011 \\
\hline Functionality and web design & $0.220^{*}$ & 3.065 & 0.003 & $0.172 *$ & 2.379 & 0.018 \\
\hline Intensive shopping & $0.367 * *$ & 5.533 & 0.000 & $0.309 * *$ & 4.626 & 0.000 \\
\hline F-value & \multicolumn{3}{|c|}{$39.380 * *$} & \multicolumn{3}{|c|}{$37.836^{* *}$} \\
\hline $\mathrm{R}^{2} /$ adjusted $\mathrm{R}^{2}$ & \multicolumn{3}{|c|}{$0.475 / 0.463$} & \multicolumn{3}{|c|}{$0.465 / 0.453$} \\
\hline
\end{tabular}

* Significant at $p<0.05, * *$ Significant at $p<0.01$

Table 4. Results of Regression Analysis on Factors Affecting Trust and Satisfaction in Experienced Buyers $(\mathrm{n}=248)$

\begin{tabular}{|c|c|c|c|c|c|c|}
\hline \multirow{2}{*}{ Independent Variables } & \multicolumn{3}{|c|}{ Ongoing Trust } & \multicolumn{3}{|c|}{ Satisfaction } \\
\hline & $\beta$ (Beta) & T-value & Sig. level & $\beta$ (Beta) & T-value & Sig. level \\
\hline Information quality and search capability & $0.231 * *$ & 3.766 & 0.000 & $0.274 * *$ & 4.273 & 0.000 \\
\hline Security and privacy & $0.232 *$ & 3.298 & 0.001 & 0.144 & 1.953 & 0.052 \\
\hline Functionality and web design & 0.014 & 0.233 & 0.816 & 0.114 & 1.761 & 0.079 \\
\hline Intensive shopping & $0.231 * *$ & 4.397 & 0.000 & $0.167 *$ & 3.032 & 0.003 \\
\hline Fulfillment and responsiveness & $0.208^{*}$ & 3.239 & 0.001 & $0.186^{*}$ & 2.776 & 0.006 \\
\hline F-value & \multicolumn{3}{|c|}{$60.424 * *$} & \multicolumn{3}{|c|}{$50.874 * *$} \\
\hline $\mathrm{R}^{2}$ /adjusted $\mathrm{R}^{2}$ & \multicolumn{3}{|c|}{$0.555 / 0.546$} & \multicolumn{3}{|c|}{$0.512 / 0.502$} \\
\hline
\end{tabular}

$*$ Significant at $p<0.05, * *$ Significant at $p<0.01$ 
In order to clarify the effect of each quality component for trust and satisfaction, regression analysis was performed with both inexperienced and experienced buyers. The results of regression analysis, as provided in Table 3 and 4, indicate that "intensive shopping" is the most important factor for boosting both initial trust and satisfaction among inexperienced buyers, while "information quality and search capability" is the most important component affecting ongoing trust and satisfaction in experienced buyers. This can be indicated that customers who are familiar with online shopping process would increasingly pay attention to useful information provided by the website.

Based on the findings from a drawn sample of this study, in order to persuade inexperienced buyers during the initial phase of customer engagement, the website administrator should be concerned about the quality criteria focus on: 1) intensive shopping, 2) functionality and web design, 3) security and privacy, and 4) information quality, respectively. While the important criteria for experienced buyers are: 1) information quality and search capability, 2) fulfillment and responsiveness, and 3 ) intensive shopping, respectively.

According to the results of regression analysis in Table 3 and 4, our findings differ from the previous studies in some aspects. Firstly, we were surprised to find that information quality has no significant effect on initial trust. This finding is in contrast to the result of the empirical study carried out by Kim et al. [7]. A possible explanation for this aspect may be that information quality is not yet sound to prescribe as the generalized activation of initial trust.

Secondly, the study by Liu et al. [18] found that appealing layout has a significant effect on satisfaction in experienced buyers, while we did not find this effect in our analysis. On the other hand, our findings indicate that "information quality and search capability" is the most important factor that shows a significant effect on trust and satisfaction among experienced buyers. As a result, the attributes that should be focused in order to respond to the perception of experienced buyers are the attributes that are relevant to effective search rather that appealing design.

\section{GENERATING PREDICTION EQUATION}

In this section, prediction equations are generated to predict trust and satisfaction values for both inexperienced and experienced buyers. Trust and satisfaction values are performed with fuzzy linguistic approach in order to create trust management strategy.

Based on the quality criteria in accordance with customer perceptions and the results of regression analysis presented in the previous section, we can generate the equations for predicting trust and satisfaction along with the entire e-commerce process by using equations (1) and (2).

$$
\begin{gathered}
B_{i}=\beta_{i} \frac{S D_{Y}}{S D_{X_{i}}} . \\
A=\bar{Y}-\left(B_{1}\right)\left(\bar{X}_{1}\right)-\left(B_{2}\right)\left(\bar{X}_{2}\right)-\ldots-\left(B_{n}\right)\left(\bar{X}_{n}\right) .
\end{gathered}
$$

With equation (1), we can calculate $\mathrm{Bi}$ or the coefficient of $i$ from each $\beta$ (Beta), as provided in Tables 3 and 4. While equation (2) is used to calculate $\mathrm{A}$ or a constant value for the linear equation. Equations (3) to (6) that are derived after operating equations (1) and (2) are the resulting equations that can be used to predict trust and satisfaction for both inexperienced and experience buyers.

$$
T_{i n i}=0.837+0.158 S P+0.241 F W D+0.381 I S .
$$

We can use equation (3) to predict the initial trust for inexperienced buyers that is represented by Tini. The factors that show a significant effect on initial trust are security and privacy (SP), functionality and web design (FWD), and intensive shopping (IS), as shown by the empirical results in Table 3 .

$$
S_{\text {inep }}=-0.132+0.192 I Q+0.240 S P+0.206 F W D+0.405 I S
$$

Equation 4 represents a linear equation that is used to predict satisfaction among inexperienced buyers that is illustrated by Sinep. The factors that affect satisfaction for the initial stage are information quality (IQ), security and privacy (SP), functionality and web design (FWD), and intensive shopping (IS), as provided by the results of regression analysis in Table 3.

$T_{\text {ong }}=-0.514+0.291 I Q S+0.280 S P+0.298 I S+0.249 F R$.

We can use equation (5) to predict ongoing trust for experienced buyers that is represented by Tong. The factors that affect ongoing trust are information quality and search capability (IQS), security and privacy (SP), intensive shopping (IS), and fulfillment and responsiveness (FR), as shown by the empirical results in Table 4.

$$
S_{e p}=1.025+0.335 I Q S+0.183 I S+0.216 F R
$$

Equation (6) represents a linear equation that is used to predict satisfaction for experienced buyers that is illustrated by Sep. The factors that affect the satisfaction for ongoing stage are information quality and search capability (IQS), intensive shopping (IS), and fulfillment and responsiveness (FR), as provided by the results of regression analysis in Table 4. 


\section{DESCRIBING PREDICTION RESULTS WITH FUZZY MEMBERSHIP FUNCTIONS}

As presented in the previous section, equations (3) to (6) will generate the results as a real number. With these results, it is difficult to determine what level of trust and satisfaction that should be assigned. We therefore decided to apply the obtained results with fuzzy membership functions in order to enable us to provide more precise answers with human intuitions common sense [26].

Fig. 2 displays the membership functions for $x_{\text {output }}$ that can be identified in terms of high, medium, or low. According to these linguistic terms, we can define the boundary of membership functions for $T_{i n i}, S_{\text {inep }}, T_{\text {ong }}$, and $S_{e p}$, as provided in equations (7) to (9).

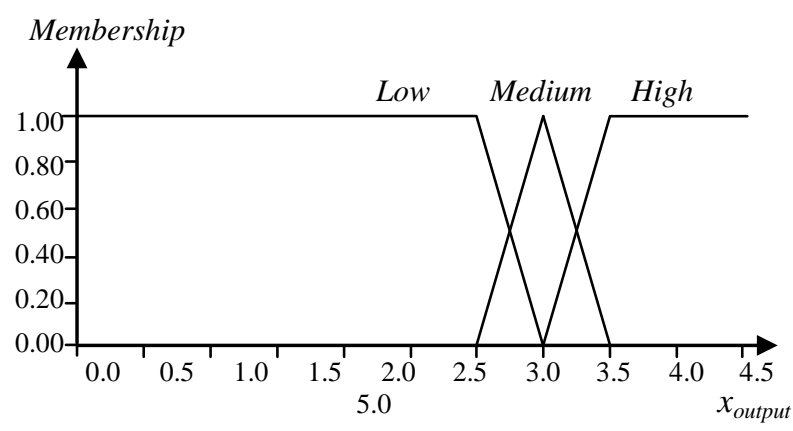

Fig 2. Membership functions for the output of prediction equations (3) to (6)

$$
\begin{gathered}
\mu_{\text {Low }}\left(x_{\text {output }}\right)=\left\{\begin{array}{cc}
1, & x \leq 3.00 \\
(3.50-x) / 0.50,3.00 & <x<3.50 \\
0, & x \geq 3.50
\end{array}\right. \\
\mu_{\text {Medium }}\left(x_{\text {output }}\right)=\left\{\begin{array}{cc}
0, & x \leq 3.00, x \geq 4.00 \\
(x-3.00) / 0.50, & 3.00<x \leq 3.50 \\
(4.00-x) / 0.50, & 3.50<x<4.00
\end{array}\right. \\
\mu_{\text {High }}\left(x_{\text {output }}\right)=\left\{\begin{array}{cc}
0, & x \leq 3.50 \\
(x-3.50) / 0.50, & 3.50<x<4.00 \\
1, & x \geq 4.00
\end{array} .\right.
\end{gathered}
$$

\section{TRUST MANAGEMENT STRATEGY}

While combining the prediction equations that derived from regression analysis with fuzzy membership functions, we therefore can identify trust management strategy that is consistent with overall buyer interaction through the e-commerce system. Trust management for this study is presented in a broader view in order to leverage both trust and satisfaction by using quality criteria that affect both of these factors. The proposed strategic trust can be divided into four strategies, as follows.

\section{A. Initial Trust Strategy}

The strategy for building initial trust for inexperienced buyers can be established based on the final results of website assessment. If the initial trust value is identified with linguistic labels low or medium, it can be interpreted that websites can not be able to create a system that identifies good practice in the following aspects: 1) security and privacy, 2) functionality and web design, and 3) intensive shopping. Websites with low or medium initial trust groups should develop the above quality criteria to improve their capability that respond poorly to inexperienced buyers. As a precaution, the websites that can build high initial trust for inexperienced buyers should be aware that trust can change over time. Therefore, the website administrators should assess their website performance against their competitors regularly.

\section{B. Strategy to Satisfy Inexperienced Buyers}

If a total score of quality criteria assessment brings the fuzzy membership of satisfaction for inexperienced buyers falling in the linguistic label low or medium, it can be indicated that the websites cannot perform well in the following criteria: 1) information quality, 2) security and privacy, 3) functionality and web design, and 4) intensive shopping. The internal operations that do not fully serve these criteria will make inexperienced buyers hesitate to purchase products or services from the visited websites. In contrast, the websites that can leverage inexperienced buyers' satisfaction at a high level will reach the ability to lead an actual purchasing decision [13]. The website administrator should maintain this satisfiable capability, as well as providing additional value of services for the next purchase.

\section{Ongoing Trust Strategy}

Even if experience buyers have more trust in their visited websites [8], but the websites that derived a low level of ongoing trust may neglect to perform actions in response to quality criteria in some aspects, as follows: 1) information quality and search capability, 2) security and privacy, 3) intensive shopping, and 4) fulfillment and responsiveness. The websites that can achieve a high level of ongoing trust should aim to develop a process that can truly protect their customers, especially in the process that helps or prevents the customers from many harmful activities on the internet.

\section{Strategy to Satisfy Experienced Buyers}

The websites that derived a low level of satisfaction for experienced buyers should pay attention to after-sales service and other value added services, in order to deliver adequate quality for their customers. The quality criteria that should be considered can be specified by three points, as follows: 1) information quality and search capability, 2 intensive shopping, and 3) fulfillment and responsiveness. Even the websites that derived a high level of satisfaction can create value added and after-sales services better than competitors, but nevertheless these websites should also 
aim to develop other additional values, especially for providing useful information and intensive shopping.

In summary, all of these proposed strategies identified from quality criteria that can leverage trust and customer satisfaction for both inexperienced and experienced buyers. These strategies are intended to serve as a guideline for the manager of e-commerce website.

\section{ROADMAP FOR ESTABLISHING TRUST MANAGEMENT STRATEGY}

Trust managements that have been carried out in the past are different depending on the context in which they are assigned. In the context related to e-business, trust management should be developed to provide the assessment that is consistence with user perceptions in each particular system. Therefore, trust management, especially in monetary services like e-commerce, is still a challenge that researchers always tend to focus as the top priority [19].

Trust management in the context of e-commerce is complex and involves many aspects beyond technical interests [5]. In previous research, there is a lack of proper trust management that can illustrate the method to link a proposed model with customer perceptions. Therefore, in this research, we propose the roadmap for establishing trust management strategy, and each strategy identified from our roadmap is driven by the quality criteria that are consistent with customer perceptions in ecommerce services. In addition, the quality criteria in our approach also correspond to the process of building trust and satisfaction with e-commerce.

In this section, we summarize five steps in the roadmap that is used to establish trust management strategy in order to provide a practical guideline for website managers, other practitioners, and other researchers in related fields.

Define the scope of trust management for e-business

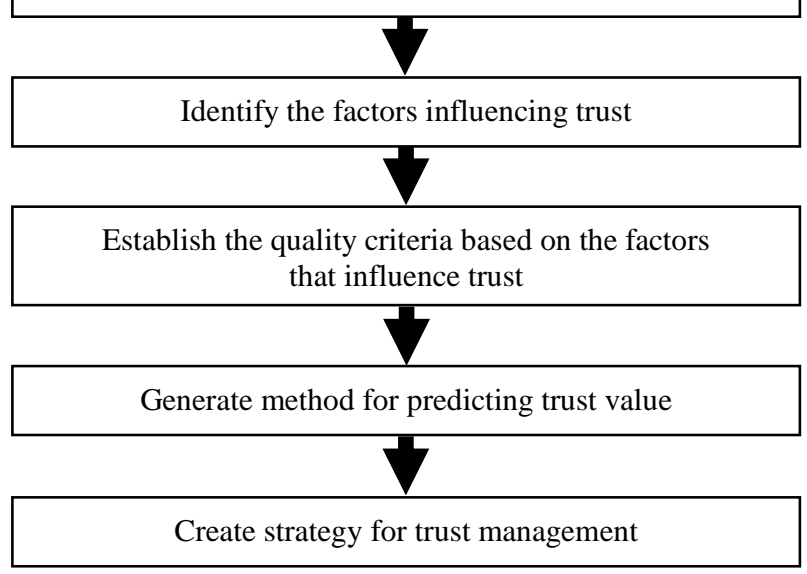

Fig 3. The roadmap for establishing trust management in e-business using quality based assessment.

Our roadmap starts with defining the scope of trust management. The scope for managing trust in this case is identified as the boundary control for trust and satisfaction that are the two important factors in the transaction process of e-commerce system. In the next step, we need to identify the factors influencing both trust and satisfaction from the literature. As a result, the quality criteria that are consistent with these factors are developed. After the required criteria has been defined and validated from the component analysis, we then generate the prediction equations by performing regression analysis. These prediction equations are produced for predicting trust value. The final step in our approach is to specify the trust management strategy. The concept of fuzzy membership functions has been applied to convert the results from prediction equations in a strategic form of the linguistic terms.

The entire process that are used to establish trust management strategy and quality criteria proposed in this article can be expressed as a sequence of stages, as shown in Fig. 3. Practitioners and researchers in e-business can also apply this roadmap in order to manage trust in other specific context.

\section{CONCLUSIONS}

The findings described in this article demonstrates many contributions, as follows: 1) Clarify the curious of perceptual different between inexperienced and experienced buyers, 2) Identify which are the quality criteria that are consistent with customer perceptions, 3) Demonstrate how to manage trust in e-business by using the proper criteria, 4) Present how to manage trust with the dynamic situation based on buyer experiences in ecommerce system, 5) Demonstrate how to apply prediction equations with fuzzy membership functions for generating trust management strategy, and 6) Summarize the practical roadmap for establishing trust management strategy for practitioners and researchers in other related fields.

As in most studies, there are some limitations to this research study that can be summarized as follows: 1) This study collected data from cross-sectional experiments among students and employees in Thailand. Therefore, a future data collection should be further investigated for a longitudinal study. 2) Prediction equations that are presented in this study are based on customer perceptions in Thailand. If other researchers aim to build prediction equations in other regions, they can use quality criteria proposed in section III and conduct a survey to rank the importance of factors related to trust and satisfaction in those regions. 3) Trust management proposed in this study addresses only in the context of monetary based services like e-commerce. Trust management for ebusiness in other context should further address quality criteria that are consistent with that specific context. And finally, 4) Affecting from cultural and social sensitivity are not included in the scope of this study.

\section{REFERENCES}

[1] C. C. Wang, "Building consumers' trust based on pick-up goods behavior in the convenience stores in Taiwan," 
International Journal of Information Engineering and Electronic Business, vol. 4, no. 2, 2012, pp. 25-33.

[2] Z. Ren and T. M. Hassan, "Trust in e-commerce," in EBusiness in Construction, C. J. Anumba and K. Ruikar, Eds, Blackwell Publishing, 2008, pp. 195-210.

[3] A. N. H. Zaied, "Barriers to e-commerce adoption in Egyptian SMEs," International Journal of Information Engineering and Electronic Business, vol. 4, no. 3, 2012, pp. 9-18.

[4] Y. Wang and K. Lin, "Reputation-oriented trustworthy Computing in e-commerce environments," IEEE Internet Computing, vol. 12, no. 4, 2008, pp. 55-59.

[5] D. J. Kim, Y. Song, S. Braynov, and H. R. Rao, "A multidimensional trust formation model in B-to-C ecommerce: A conceptual framework and content analyses of academia/practitioner perspectives," Decision Support Systems, vol. 20, no. 2, 2005, pp. 143-165.

[6] D. Gefen and D. W. Straub, "Managing user trust in B2C e-services," E-Service Journal, vol. 2, no. 2, 2003 pp. 7-24.

[7] H. W. Kim, Y. Xu, and J. Koh, "A comparison of online trust building factors between potential customers and repeat customers," Journal of the Association for Information Systems, vol. 5, no. 10, 2004, pp. 392-420.

[8] D. Gefen, E. Karahanna, and D. W. Straub, "Inexperience and experience with online stores: The importance of TAM and trust," IEEE Transactions on Engineering Management, vol. 50, no. 3, 2003, pp. 307-321.

[9] H. H. Chang and S. W. Chen, "The impact of online store environment cues on purchase intention: Trust and perceived risk as a mediator," Online Information Review, vol. 32, no. 6, 2008, pp. 818-841.

[10] C. Chiu, C. Chang, H. Cheng, and Y. Fang, "Determinants of customer repurchase intention in online shopping," Online Information Review, vol. 33, no. 4, 2009, pp. 761784.

[11] T. Falk, M. Hammerschmidt, and J. J. Schepers, "The service quality-satisfaction link revisited: Exploring asymmetries and dynamics," Journal of the Academy of Marketing Science, vol. 38, no. 3, 2010, pp. 288-302.

[12] S. Ha and L. Stoel, "Consumer e-shopping acceptance: antecedents in a technology acceptance model," Journal of Business Research, vol. 62, no. 5, 2009, pp. 565-571.

[13] R. Jairak and P. Praneetpolgrang, "The development of a new capability maturity model for assessing trust in B2C ecommerce services," Proceedings of the ICIEIS'11, Part II, CCIS 252, 2011, pp. 448-462.

[14] D. J. Kim, D. L. Ferrin, and H. R. Rao, "A trust-based consumer decision-Making model in electronic commerce: The role of trust, perceived risk, and their antecedents," Decision Support Systems, vol. 44, no. 2, 2008, pp. 544564.

[15] J. Kim, B. Jin, and J. L. Swinney, "The role of etail quality, e-satisfaction and e-trust in online loyalty development process," Journal of Retailing and Consumer Services, vol. 16, no. 4, 2009, pp. 239-247.

[16] C. X. Ou and C. L. Sia, "To trust or to distrust, That is the question-investigating the trust-distrust paradox," Communications of the ACM, vol. 52, no. 5, 2009, pp. 135-139.

[17] T. Zhou, Y. Lu, and B. Wang, "The relative importance of website design quality and service quality in determining consumers' online repurchase behavior," Information Systems Management, vol. 26, no. 4, 2009, pp. 327-337.

[18] C. Liu, S. Forsythe, and W. C. Black, "Beyond adoption: sustaining online shopping," The International Review of Retail, Distribution and Consumer Research, vol. 21, no. 1, 2011, pp. 71-93.
[19] C. Liu, "Human-machine trust interaction: A technical overview," International Journal of Dependable and Trustworthy Information Systems, vol. 1, no. 4, 2010, pp. 61-74.

[20] D. J. Kim, "An investigating of the effect of online consumer trust on expectation, satisfaction, and postexpectation," Information System and E-Business Management, vol. 10, no. 2, 2012, pp. 219-240.

[21] D. H. McKnight, V. Choudhury, and C. Kacmar, "Trust in e-commerce vendors: A two-stage model," Proceedings of the Twenty First International Conference on Information Systems, Association for Information Systems Atlanta, GA USA, 2000, pp. 532-536.

[22] H. Wang, "How to stick to online consumers: CRM perspective," Proceedings of the ICCIC'11, Part III, CCIS 233, 2011, pp. 224-231.

[23] L. Yaobin and Z. Tao, “A Research of consumers' initial trust in online stores in China," Journal of Research and Practice in Information Technology, vol. 39, no. 3, 2007, pp. 167-180.

[24] D. Gefen, E. Karahanna, and D. W. Straub, "Trust and TAM in online shopping: An integrated model," MIS Quarterly, vol. 27, no. 1, 2003, pp. 51-90.

[25] P. Bedi and V. Gaur, "Trust based prioritization of quality attributes," The International Arab Journal of Information Technology, vol. 5, no. 3, 2008, pp. 223-229.

[26] F. Akhter, D. Hobbs, and Z. Maamar, "A fuzzy logic-based system for assessing the level of business-to-consumer (B2C) trust in electronic commerce," Expert Systems with Applications, 28, 2005, pp. 623-628.

\section{Authors' Profiles}

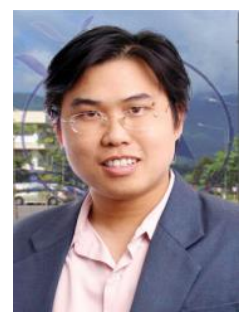

Rath Jairak received his B.Sc. in Photographic Science and Printing Technology from Chulalongkorn University, Bangkok, Thailand, in 1999, and his M.S. in Information Technology and Management from Chiang Mai University, Chiang Mai, Thailand, in 2005. $\mathrm{He}$ is currently a Ph.D candidate in Information Technology, Doctor of Philosophy Program in Information Technology, School of Information Technology, Sripatum University, Thailand. Rath is also a lecturer at Chiang Mai Rajabhat University. His research interests include e-Commerce, e-Services, and trust management. His current focus is on trust development in B2C e-Commerce services. In addition, he published more than ten papers in these areas.

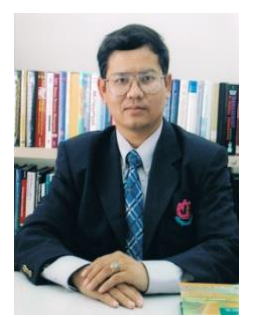

Prasong Praneetpolgrang received the B.Sc. ( $1^{\text {st }}$ Hons) In Electrical Engineering from the Royal Thai Air Force Academy, Bangkok, THAILAND, in 1987, the M.S. in Computer Engineering, 1989, the M.S. in Electrical Engineering, 1993, and the Ph.D degree in Computer Engineering from Florida Institute of Technology, Melbourne, Florida, USA, in 1994. He currently has the rank of associate professor at the School of Information Technology, Sripatum University, Thailand. His research interests are in the areas of Computer and Information Security, Trust Management and IT Governance, e-Commerce and Cloud Applications. Dr. Prasong Praneetpolgrang has more than 100 
published articles in these areas. He has served on program committees of both national and international conference on Computer Science and Engineering, Information Technology and e-Business. He is also member of IEEE, and ACM. He has recorded in Who's Who in the world in Information Technology.

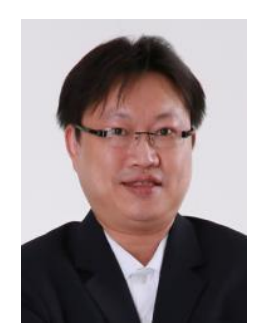

Nivet Chirawichitchai received his B.B.A. in Industrial Management and B.A. in Mass Communication from Ramkhamhaeng University, M.S. in Computer Technology and the Ph.D degree in Information Technology from King Mongkut's Institute of Technology North Bangkok, Thailand. He currently has the rank of director, Master of Science program in Computer Information Systems, School of
Information Technology, Sripatum University, Thailand. His main research interests are in the field of machine learning, data mining and knowledge representation and reasoning. Dr. Nivet Chirawichitchai has several published articles in these fields. He is also a lecturer for undergraduate and graduate level in Information Technology Department, Sripatum University.

How to cite this paper: Rath Jairak, Prasong Praneetpolgrang, Nivet Chirawichitchai,"A Roadmap for Establishing Trust Management Strategy in E-Commerce Services Using Quality Based Assessment", IJIEEB, vol.6, no.5, pp.1-9, 2014. DOI: 10.5815/ijieeb.2014.05.01 